\title{
Regulation of Monocyte Chemoattractant Protein-1 Through Angiotensin II Type 1 Receptor in Prostate Cancer
}

\author{
Suguru Shirotake, ${ }^{*}$ Akira Miyajima, ${ }^{*}$ \\ Takeo Kosaka, ${ }^{*}$ Nobuyuki Tanaka, ${ }^{*}$ Eiji Kikuchi, ${ }^{*}$ \\ Shuji Mikami, ${ }^{\dagger}$ Yasunori Okada, ${ }^{\dagger}$ and \\ Mototsugu Oya* \\ From the Departments of Urology* and Pathology, Keio \\ University School of Medicine, Tokyo, Japan
}

\begin{abstract}
Monocyte chemoattractant protein-1 (MCP-1/CCL2) is reported to contribute to tumor progression and is regulated by the renin-angiotensin system in hypertensive disease. In this study, we investigated the clinical outcome of MCP-1 expression in patients with prostate cancer (CaP) and the regulation of MCP-1 through angiotensin II (AngII) type 1 receptor (AT1R) in CaP. Specimens were obtained from 138 CaP patients and analyzed by immunostaining for both MCP-1 and macrophages. We investigated the regulation of MCP-1 expression through AT1R both in vivo and in vitro using three human prostate cancer cell lines: LNCaP, C4-2, and C4-2AT6. Specimens with a high Gleason score $(\geq 7)$ and a high pathological classification ( $\leq$ pT 3 ), and those with castration-resistant prostate cancer showed significantly higher MCP-1 expression and higher macrophage infiltration than low malignant potential CaP. High MCP-1 expression in CaP correlated significantly with high prostatespecific antigen (PSA) recurrence rates. AngII induced significantly higher MCP-1 levels in C4-2AT6 than in LNCaP, whereas AT1R blockade (ARB) inhibited MCP-1 production via the inhibition of the PI3K/Akt pathway in C4-2AT6. ARB also significantly suppressed MCP-1 expression in C4-2AT6 tumors. Our study is the first to demonstrate that both high MCP-1 expression and high macrophage infiltration in CaP specimens correlate with a high PSA recurrence rate and that $A R B$ inhibits MCP-1 expression through the PI3K/Akt pathway and blocks macrophage infiltration in castration-resistant prostate cancer. (Am J Pathol 2012, 180:1008-1016; DOI: 10.1016/j.ajpath.2011.11.027)
\end{abstract}

Prostate cancer $(\mathrm{CaP})$ is one of the most common cancers and the second leading cause of cancer-related death in men in the United States. ${ }^{1}$ Patients with advanced and metastatic CaP are treated mainly by androgen ablation. Unfortunately, in most of these patients, the tumor will acquire castration independence and then continue to be an incurable disease, termed castration-resistant prostate cancer (CRPC). ${ }^{2}$ Recently, novel therapeutic strategies for malignancies have focused on targeting the surrounding host microenvironment as well as the tumor cells. ${ }^{3}$

Previous studies have demonstrated that macrophages, specifically tumor-associated macrophages, promote tumorigenesis and that there is a significant correlation between increased macrophage infiltration and poor patient prognosis in thyroid ${ }^{4}$ and hepatocellular cancers. ${ }^{5}$ On the other hand, one noteworthy report found that high macrophage infiltration in tumor islets correlates with a good prognosis in patients with non-small cell lung cancer. ${ }^{6}$ In CaP, it remains controversial as to whether macrophage infiltration in tumor lesions is an indicator of clinicopathological characteristics and clinical outcome. .,8 $^{7}$

Monocyte chemoattractant protein-1 (MCP-1/CCL2) is responsible for the recruitment of immune cells such as macrophages to sites of inflammation and has been shown to have a direct effect on endothelial cells in promoting angiogenesis. ${ }^{9}$ MCP-1 also regulates tumor growth, migration of tumor cells, and tumor angiogenesis $^{9}$ by promoting macrophage mobilization and infiltration into the tumor bed in breast, lung, colorectal, and prostate cancers. ${ }^{9-12}$ More recently, in CaP in particular, MCP-1 is reported to have multiple roles, mainly through activation of the phosphatidylinositol 3-kinase/protein ki-

Supported in part by Grants-in-Aid for Scientific Research (\#23791785 to S.S., \#22591777 to A.M., \#21390455 to M.O., and \#20013040 to Y.O.) from the Ministry of Education, Culture, Sports, Science, and Technology of Japan.

Accepted for publication November 17, 2011.

Supplemental material for this article can be found at http://ajp. amjpathol.org or at doi: 10.1016/j.ajpath.2011.11.027.

Address reprint requests to Akira Miyajima, M.D., Department of Urology, Keio University School of Medicine, 35, Shinanomachi, Shinjuku-ku, Tokyo 160-0016, Japan. E-mail: akiram@sc.itc.keio.ac.jp. 
nase $\mathrm{B}$ (PI3K/Akt) pathway in promoting CaP growth. ${ }^{13}$ However, the molecular mechanisms of upstream regulation of MCP-1 expression in tumors remain unknown. Some clinical studies showed that MCP-1 expression in $\mathrm{CaP}$ was correlated with malignant potential and tumor development of $\mathrm{CaP} .{ }^{11}$ However, since the number of the subjects was small and limited, the clinical role of MCP-1 expression in $\mathrm{CaP}$ still has not been studied in sufficient detail.

The effects of cancer-related inflammation and angiogenesis on malignancy and disease progression have been reviewed. ${ }^{14}$ Accumulated evidence suggests that the renin-angiotensin system participates in the regulation of cancer inflammation and tumor angiogenesis. ${ }^{15} \mathrm{It}$ is known that angiotensin II type 1 receptor (AT1R), which is a component of the renin-angiotensin system, regulates MCP-1 as an inflammatory chemokine in hypertensive vascular disease ${ }^{16}$; however, there have not been any reports on the regulation of MCP-1 expression through AT1R in CaP.

In the present study, we examined the clinical role and regulation of MCP-1 expression through AT1R in CaP.

\section{Materials and Methods}

\section{Antibodies and Reagents}

Angiotensin II and mouse monoclonal antibody for $\beta$-actin were purchased from Sigma (St. Louis, MO). Rabbit polyclonal antibody for AT1R and NF $\mathrm{N}^{\mathrm{B}}$ p65 were purchased from Santa Cruz Biotechnology (Santa Cruz, CA). Candesartan (CV11974 and TCV116) was provided by Takeda Pharmaceutical Co (Tokyo, Japan). CV11974 and TCV116 are active metabolites of candesartan and were used for the in vitro and in vivo experiments. Antibodies against pan Akt and phospho-Akt $\left(\mathrm{Ser}^{473}\right)$, ERK $1 / 2$ and phospho-ERK1/2 (Thr $\left.{ }^{185} / \mathrm{Tyr}^{189}\right)$, JNK and phospho-JNK $\left(\mathrm{Ser}^{473}\right), \mathrm{p} 38$ and phospho-p38 $\left(\mathrm{Thr}^{180} /\right.$ $\mathrm{Tyr}^{182}$ ), and the PI3 kinase inhibitor LY294002 were purchased from Cell Signaling Technology (Danvers, MA). Recombinant human MCP-1 (rhMCP-1) and anti-human MCP-1 monoclonal antibody were purchased from R\&D Systems (Minneapolis, MN). F4/80 (Cl:A3-1) antibody was obtained from Abcam (Cambridge, MA), and CD68 (Cl:PGM1) was purchased from Dako (Glostrup, Denmark).

\section{Clinical Samples and Clinicopathological Features}

Archival paraffin-embedded sections were obtained from 138 patients with $\mathrm{CaP}$ diagnosed at Keio University Hospital. One hundred twenty-one patients underwent curative surgery that included radical prostatectomy for localized CaP between January 2000 and December 2003. None of the patients had received hormonal treatment before the operation. The characteristics of these patients are shown in Table 1. After radical prostatectomy, the patients were followed by serum prostate-specific antigen (PSA) level and imaging studies. PSA relapse was defined by an elevation of serum PSA levels at three
Table 1. Clinical and Pathological Characteristics of the Patients with Androgen-Dependent Prostate Cancer

\begin{tabular}{lc}
\hline \multicolumn{1}{c}{ Variable } & Cases \\
\hline Age (years) & \\
Mean (range) & $66 \pm 5(50-75)$ \\
PSA (ng/mL) & $10.9 \pm 7.3(3.9-49.9)$ \\
$\quad$ Mean (range) & 52 \\
Pathological T classification & 69 \\
$\leq$ pT2 & 54 \\
< pT2 & 67 \\
Gleason score & \\
$\leq 6$ & $68 \pm 31(12-111)$ \\
$\geq 7$ &
\end{tabular}

consecutive measurements. The remaining 17 prostate specimens were also consecutively selected from the archival paraffin-embedded sections of patients who died of CRPC and had undergone autopsy at our hospital. The average age of the patients with CRPC was 70 years (range, 65 to 82 years). The Gleason score of all 17 samples was more than 8 , and all were clinically stage IV. All of these patients had been subjected to androgen ablation. Histology of the specimens was evaluated by two independent pathologists using hematoxylin and eosin-stained slides. All study participants provided informed consent, and the study design was approved by an ethics review board.

\section{Cell Lines and Culture}

LNCaP cells and C4-2 cells were cultured in RPMI 1640 supplemented with $1 \%$ penicillin/streptomycin and $10 \%$ fetal bovine serum (FBS), at $37^{\circ} \mathrm{C}$ in a humidified $5 \% \mathrm{CO}_{2}$ atmosphere. As previously reported, we additionally used C4-2AT6 (androgen-ablated treatment for 6 months) cells, which were obtained from $\mathrm{C} 4-2$ cells that were grown in RPMI 1640 containing 10\% charcoalstripped fetal bovine serum with $1 \%$ antibiotics, at $37^{\circ} \mathrm{C}$ in a humidified $5 \% \mathrm{CO}_{2}$ atmosphere. ${ }^{17} \mathrm{LNCaP}$ is generally used as an androgen-dependent prostate cancer cell line, and C4-2 is also used as an androgen-independent prostate cancer cell line. C4-2AT6 is a C4-2 subline with additionally acquired malignant potential including androgen independency and aggressive angiogenesis. ${ }^{17}$

\section{Murine Xenograft Prostate Cancer Model}

Six-week-old male athymic nude BALB/C mice were castrated by scrotal incision under local anesthesia, and were used to create a xenograft model with C4-2 and C4-2AT6 cells. Twenty mice per group were subcutaneously inoculated with $5.0 \times 10^{6}$ cells suspended in 100 $\mu \mathrm{L}$ of Matrigel (Becton Dickinson Labware; BD, Franklin Lakes, NJ). Tumor volume was calculated using the formula: tumor volume $\left(\mathrm{mm}^{3}\right)=$ length $\times$ width $\times$ height $\times$ 0.52 . Tumors were measured every 4 days for 20 days once the tumor volume had reached 50 to $80 \mathrm{~mm}^{3}$, which was defined as baseline. The animals were sacrificed 
and the subcutaneous tumors were harvested on day 20 . In the AT1R blockade (ARB) administration model, the treatment was started on day 1.

\section{Cell Extracts and Western Blot Analysis}

Whole-cell extracts were obtained using radioimmunoprecipitation assay buffer [50 mmol/L, Tris- $\mathrm{HCl}(\mathrm{pH} 7.5)$, $150 \mathrm{mmol} / \mathrm{L} \mathrm{NaCl}, 1 \% \mathrm{NP}-40,0.5 \%$ deoxycholate, $0.1 \%$ SDS], containing protease inhibitors. Proteins were extracted from the cytoplasm and nucleus separately according to the standard methods. ${ }^{17}$ For Western blot analysis, equal amounts of protein were electrophoretically separated by SDS-PAGE and transferred to TransBlot nitrocellulose membranes (Bio-Rad, Hercules, CA). Membranes were incubated overnight with primary antibody. They were then incubated with peroxidase-labeled secondary antibody (Dako). The signals were detected by enhanced chemiluminescence reagents (ECL Plus Western Blotting Detection System; Amersham Pharmacia Biotech, Uppsala, Sweden) and analyzed. The intensity was quantified using the LAS 4000 system (Fuji Film, Tokyo, Japan).

\section{Immunohistochemical Staining and Scoring}

Xenograft tumors were harvested and placed in fresh $10 \%$ formalin. The formalin-fixed paraffin-embedded sections $(4 \mu \mathrm{m})$ were deparaffinized, rehydrated, and then antigen retrieval was performed with Target Retrieval Solution (Dako) at $121^{\circ} \mathrm{C}$ for 10 minutes. Endogenous peroxidase was quenched. A blocking step was included using $1 \%$ bovine serum albumin in conjunction with avidin and biotin blocking solutions. The tissue sections were overlaid with the primary antibody and incubated at $4^{\circ} \mathrm{C}$ overnight. After incubation with a biotinylated secondary antibody, the tissue sections were incubated with avidin-biotin peroxidase complex, and color was developed with diaminobenzidine. After washing the slides, they were counterstained with hematoxylin. $\mathrm{CD}^{+} 8^{+}$cells and $\mathrm{F} 4 / 80^{+}$cells were counted in 10 randomly chosen within-tumor regions at a magnification of $\times 200$. We first determined immunoreactivity for AT1R and MCP-1 (percentage of immunostained cells to total carcinoma cells), and then the proportion score was assigned according to the percentage: $0,0 \% ; 1,1 \%$ to $24 \% ; 2,25 \%$ to $49 \% ; 3$, $50 \%$ to $74 \%$; and $4,75 \%$ to $100 \%$. The intensity score was estimated by observing the average staining intensity of positively stained cells: 0 , none; 1 , weak; 2 , moderate; and 3 , strong. The proportion and intensity scores were combined to obtain the expression score which ranged from 0 to $7 .{ }^{18}$ We classified the $\mathrm{CaP}$ cases into two groups with low (score 0 to 2 ) and high (score 3 to 7 ) expression for further statistical analyses.

\section{MCP-1 ELISA}

Cells were seeded in $60 \mathrm{~mm}^{2}$ dishes and allowed to attach at $37^{\circ} \mathrm{C}$ in a humidified atmosphere of $5 \% \mathrm{CO}_{2} /$ $95 \% \mathrm{O}_{2}$. After 24 hours, the medium was replaced with serum-free medium for 24 hours, and then the cells were incubated with conditioned medium (Angll $10^{-8} \mathrm{~mol} / \mathrm{L}$, or $10^{-7} \mathrm{~mol} / \mathrm{L}$ ). After 12 or 24 hours, the supernatant was collected, and MCP-1 was measured using a commercially available enzyme-linked immunosorbent assay (ELISA) kit (Quantikine, R\&D Systems). The protein level for MCP-1 was quantified by comparing its optical density to the standard curve for MCP-1 and normalizing it for the cell number.

\section{Statistical Analysis}

PSA relapse-free survival curves were constructed using the Kaplan-Meier method and were compared using the log-rank test. Multivariate analysis was performed using the Cox proportional hazards model with stepwise forward selection to identify factors associated with PSA relapse. The independent variables were age, preoperative PSA, Gleason score, lymphovascular invasion, macrophage infiltration, and MCP-1 expression. Data are expressed as the mean value \pm SEM. The level of significance was set at $P<0.05$. Statistical analysis was performed using Statview 5.0 software (SAS Institute, Cary, NC).

\section{Results}

\section{Correlation between MCP-1 Expression and Malignant Potential in Clinical CaP Specimens}

To study the expression of MCP-1 and the infiltration of $\mathrm{CD}^{+} 8^{+}$macrophages in $\mathrm{CaP}$, we classified clinical specimens according to the Gleason score and pathological stage, and analyzed the specimens by immunohistochemical staining. MCP-1-positive staining was observed in the tumor cells, extracellular areas surrounding neoplastic glands, and epithelial cells (Figure 1A). MCP-1 was expressed significantly higher in advanced-stage $\mathrm{CaP}$ with a higher Gleason score $(P<0.001)$ and pT3-4 $(P<0.001)$, and in CRPC $(P<0.001)$ than in low-stage $\mathrm{CaP}$ (Figure 1B). A high degree of infiltration by $\mathrm{CD}^{+} 8^{+}$ macrophages was observed within neoplastic lesions. Advanced-stage $\mathrm{CaP}$ showed significantly higher infiltration of macrophages as well as higher MCP-1 expression than low-stage $\mathrm{CaP}$ (Figure 1, A and B). When the expression score of MCP-1 was classified into a low group $(<3, n=93)$ and a high group $(\leq 3, n=45)$, CaP specimens with high MCP-1 expression showed significantly higher infiltration of $\mathrm{CD} 68^{+}$macrophages $(P<0.0001)$ in tumor lesions (Figure 1C).

\section{Correlation between MCP-1 Expression in $\mathrm{CaP}$ Specimens and PSA Recurrence}

Kaplan-Meier curves for 110 patients who had obvious and proper clinical characteristics showed that the 5-year PSA recurrence-free survival (RFS) rate was $77.0 \%$ in the low MCP-1 group ( $n=89$ ) versus $54.5 \%$ in the high MCP-1 group $(n=21)(P=0.017)$ (Figure 1D). When the patients were classified according to macrophage infiltration into low $(<15)$ and high groups $(\geq 15)$, the 5 -year recurrence-free survival rate was $80.8 \%$ in the low group 


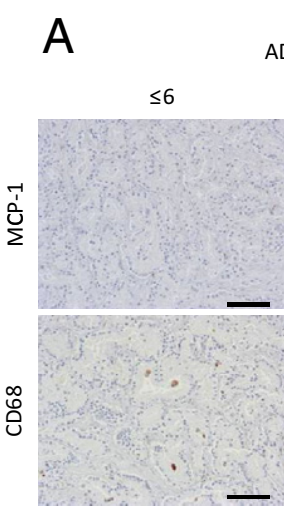

C

\section{(}

ADPC
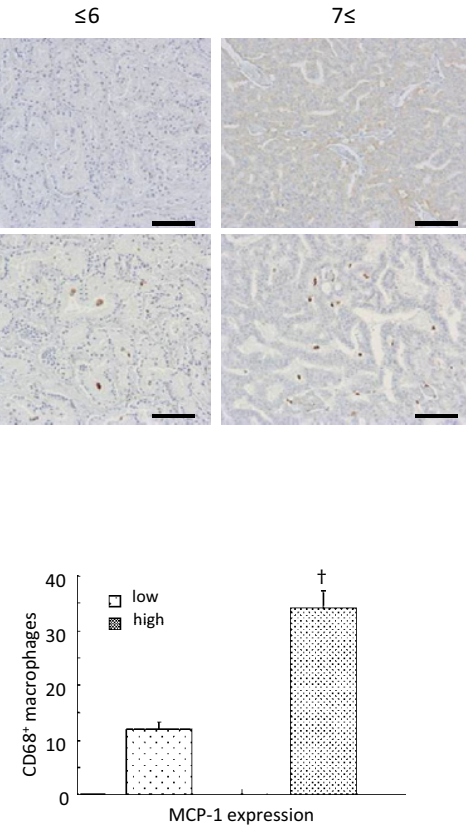

CRPC

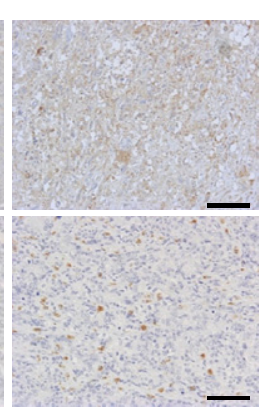

D

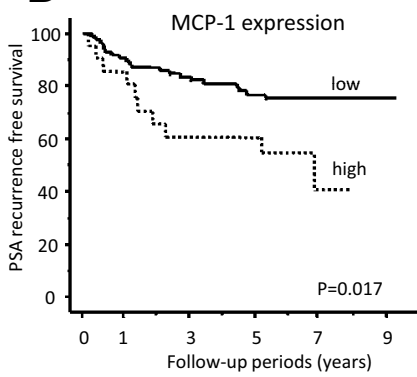

B $\quad$ MCP-1
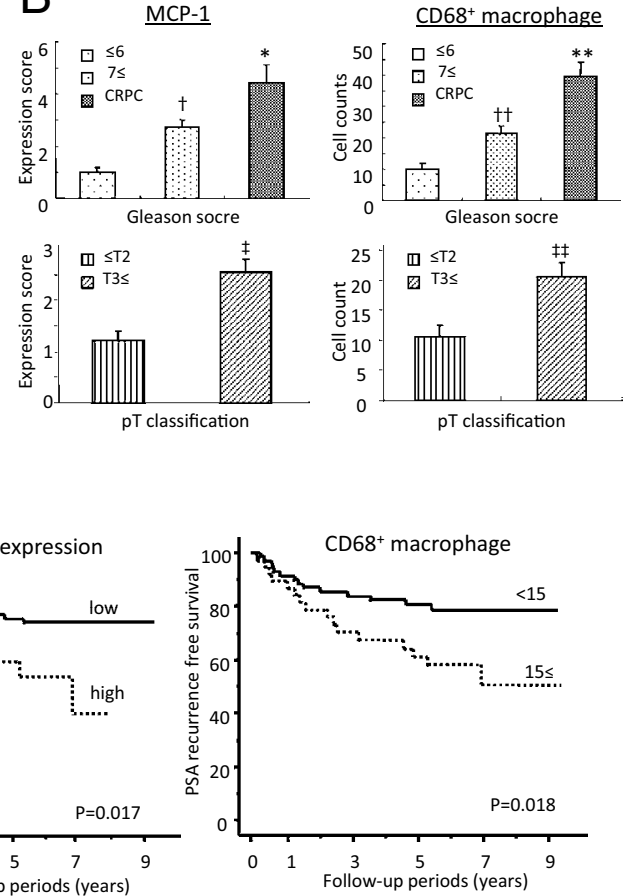

Figure 1. A and B: MCP-1 expression and CD $68^{+}$macrophages were correlated with CaP malignant potential, including androgen independency (A), Gleason score $(\mathbf{B}){ }^{\dagger} P<0.0001,{ }^{\dagger t} P<0.001$ versus Gleason score 5 and 6 specimens; ${ }^{*} P<0.05$, ${ }^{* *} P<0.0001$ versus Gleason score $\geq 7$ specimens, and pT classification, ${ }^{\ddagger} P<0.001,{ }^{\ddagger \ddagger} P<0.01$ versus $\leq \mathrm{T} 2$ specimens. Original magnification, $\times 200$. Scale bar $=100 \mu \mathrm{m}$. C: MCP-1 expression was correlated with the infiltration of $\mathrm{CD} 68^{+}$macrophages in CaP specimens. ${ }^{\dagger} P<0.0001$. D: Kaplan-Meier curves of PSA recurrence-free survival stratified by $\mathrm{CD} 68^{+}$macrophage and $\mathrm{MCP}-1$ expression.

and $57.9 \%$ in the high group $(P=0.018)$ (Figure 1D). Multivariate analysis revealed that a preoperative high PSA (15 $\leq$ ) (risk ratio, 2.48) and MCP-1 expression (risk ratio, 2.20) were independent risk factors for PSA recurrence (Table 2).

\section{Correlation between MCP-1 Expression in $\mathrm{CaP}$ Cells and Malignant Potential in Vivo and in Vitro}

We investigated the expression of MCP-1 in CaP cells using LNCaP (as an androgen-dependent prostate can-

Table 2. Univariate and Multivariate Analyses on 5-Year PSA Recurrence-Free Survival in Androgen-Dependent Prostate Cancer after Curative Surgery

\begin{tabular}{|c|c|c|c|c|c|}
\hline & \multirow[b]{2}{*}{$n$} & \multicolumn{2}{|c|}{ Univariate analysis } & \multicolumn{2}{|c|}{ Multivariate analysis } \\
\hline & & $\%$ & $P$ value & Hazard ratio $(95 \% \mathrm{Cl})$ & $P$ value \\
\hline Age & & & 0.25 & & 0.32 \\
\hline$<65$ & 37 & 69.6 & & 1 & \\
\hline$\leq 65$ & 73 & 77.9 & & $0.72(0.35-1.51)$ & \\
\hline PSA & & & 0.0024 & & 0.009 \\
\hline$<15$ & 95 & 78.6 & & 1 & \\
\hline$\leq 15$ & 15 & 42.3 & & $2.48(1.03-5.97)$ & \\
\hline GS & & & 0.21 & & 0.83 \\
\hline$\leq 6$ & 55 & 78.6 & & 1 & \\
\hline$\leq 7$ & 55 & 69.1 & & $1.10(0.48-2.48)$ & \\
\hline LVI & & & 0.068 & & 0.18 \\
\hline Negative & 91 & 77.8 & & 1 & \\
\hline Positive & 19 & 54.4 & & $1.65(0.69-3.90)$ & \\
\hline Macrophage & & & 0.018 & & 0.25 \\
\hline$<15$ & 82 & 80.8 & & 1 & \\
\hline$\leq 15$ & 28 & 57.9 & & $1.43(0.61-3.32)$ & \\
\hline MCP-1 & & & 0.017 & & $<0.05$ \\
\hline Low & 89 & 77.0 & & 1 & \\
\hline High & 21 & 54.5 & & $2.20(1.01-4.42)$ & \\
\hline
\end{tabular}


A

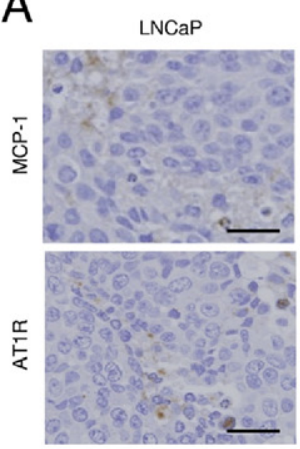

C4-2

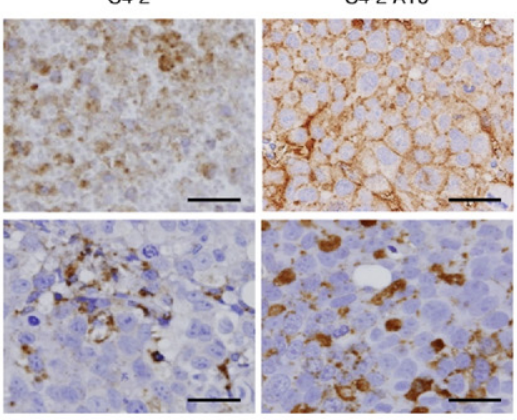

B

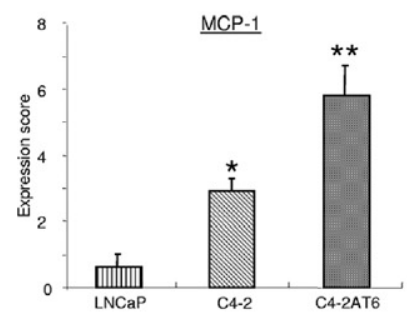

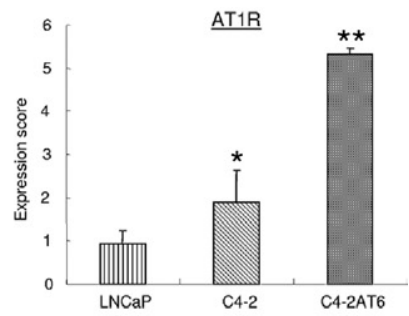

C

MCP-1

AT1R

ACTB

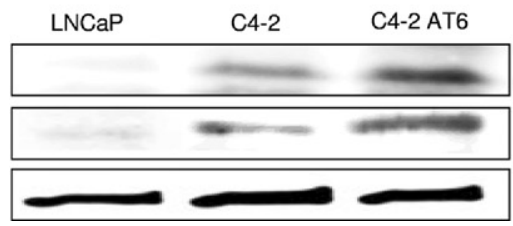

cer cell line), C4-2 (LNCaP subline; as a CRPC cell line), and C4-2AT6 (modified C4-2 cells; as an advanced CRPC cell line $)^{17}$ in vivo and in vitro. Higher expression of MCP-1 in C4-2 (over 10-fold) and C42AT6 (over 20-fold) tumors than in LNCaP tumors was observed (Figure 2, A and B, $P<0.01$ ). Higher expression of MCP-1 in C4-2 and C4-2AT6 cells than in $\mathrm{LNCaP}$ cells in vitro was also observed (Figure $2 \mathrm{C}$ ). These results obtained using these three cell lines in vivo and in vitro show that there is a correlation between MCP-1 expression in clinical specimens and castration resistance in $\mathrm{CaP}$

\section{Regulation of MCP-1 Expression through AT1R in $\mathrm{CaP}$}

It is known that the angiotensin II-AT1R (Angll-AT1R) axis regulates $\mathrm{MCP}-1$ expression in vascular smooth muscle cells. We hypothesized that MCP-1 may be regulated through the Angll-AT1R axis in CaP. By immunohistochemistry, C4-2 tumors (over twofold) and C4-2AT6 tumors (over fivefold) showed significantly higher expression of AT1R than LNCaP tumors (Figure $2, A$ and $B, P<0.01)$. This was further confirmed by immunoblotting that C4-2 cells exhibited higher AT1R expression than LNCaP cells, and C4-2AT6 cells showed higher AT1R expression than C4-2 cells (Figure 2C). MCP-1 expression by Angll and CV11974 (as an $\mathrm{ARB}$ ) was determined in $\mathrm{CaP}$ cell lines. MCP-1 production in C4-2AT6 cells was induced to a significantly higher degree by Angll $10^{-8} \mathrm{~mol} / \mathrm{L}$ at 24 hours than in C4-2 cells, whereas CV11974 10 $0^{-7} \mathrm{~mol} / \mathrm{L}$ inhibited its production in both sublines $(P<0.0001$, Figure 3). By contrast, MCP-1 was not significantly induced by Angll and was not inhibited by CV11974 in LNCaP cells (Figure 3).

\section{Inhibition of MCP-1 Expression by $A R B$ in Mouse Xenograft Models}

We evaluated the inhibitory effect of MCP-1 by TCV116 (as an ARB) in C4-2AT6 xenograft models. TCV116 treatment resulted in a dramatic inhibition of subcutaneous tumor volume (Figure 4A). Next, we immunostained tissue samples using $\mathrm{MCP}-1$ and $\mathrm{F} 4 / 80^{+}$macrophages, respectively. C4-2AT6 tumors treated with TCV116 exhibited significantly lower MCP-1 expression (about 45\%, $P=0.0033$ ) and lower macrophage infiltration (about $75 \%, P<0.001$ ) than the control group tumors (Figure 4 , $B$ and $C)$.

\section{Angll-AT1R Axis Regulates MCP-1 Expression through PI3K/Akt Signaling in C4-2AT6 Cells}

It has been reported that the Angll-AT1R axis promotes breast cancer survival via the PI3K/Akt pathway, ${ }^{19}$ and that MCP-1 acts in an autocrine manner in $\mathrm{CaP}$ progression through the PI3K/Akt pathway. ${ }^{11} \mathrm{C} 4-2$ cells are

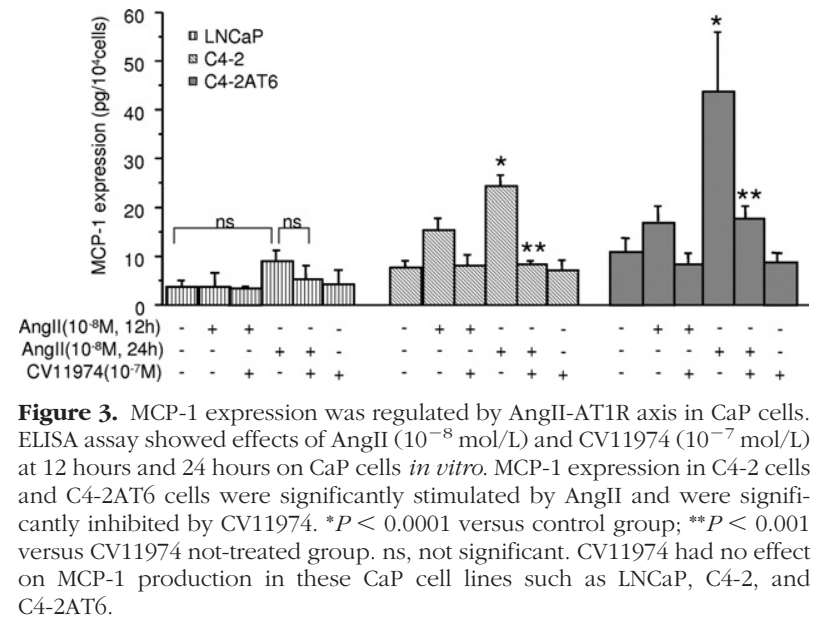



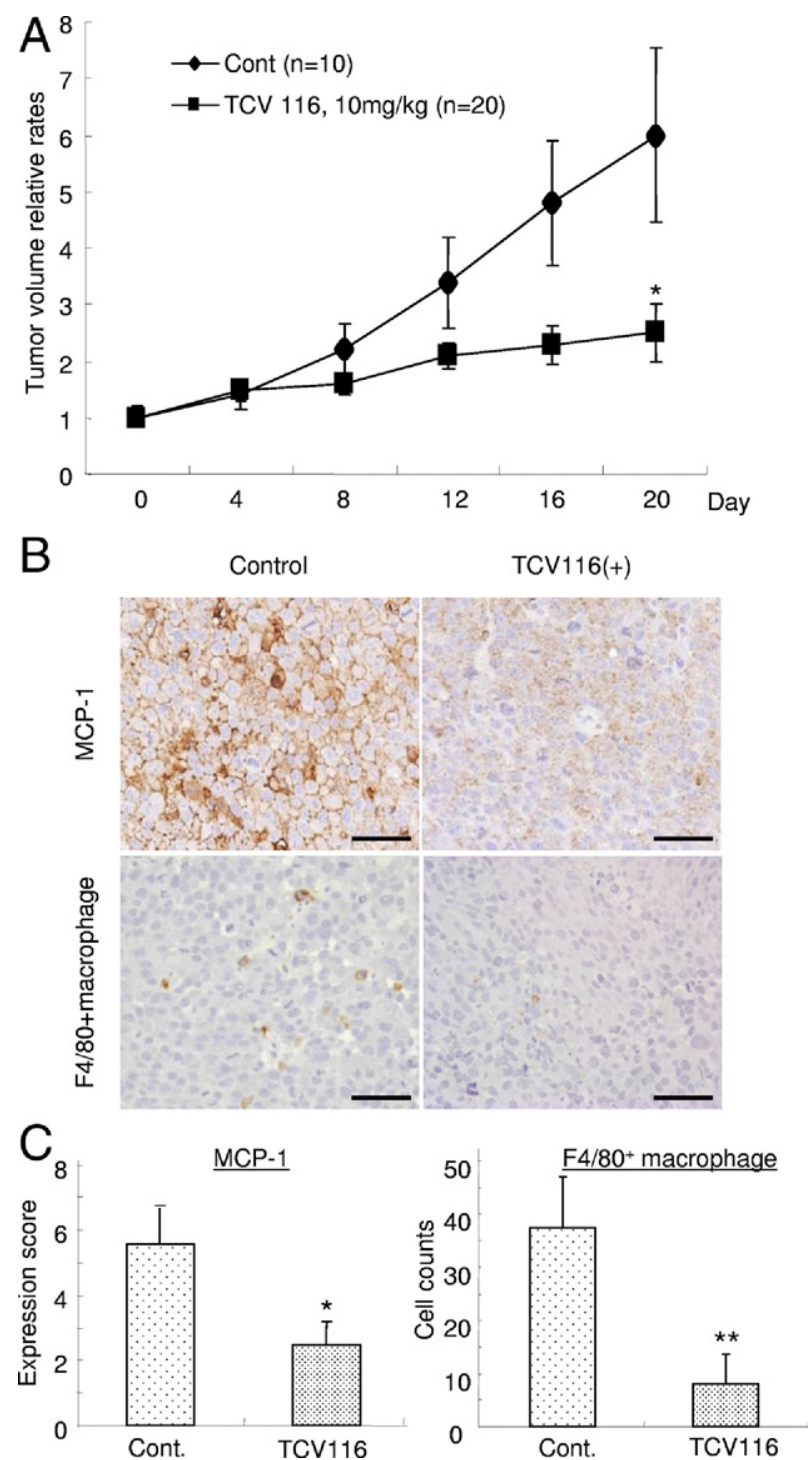

Figure 4. Efficacy of candesartan compared with PBS in C4-2AT6 xenograft models. A: Tumor burden showed significant reduction by TCV116 (10 $\mathrm{mg} / \mathrm{kg}, n=20)$ compared with the control group $(n=10) .{ }^{*} P<0.01$. B and C: $\mathrm{MCP}-1$ expression and $\mathrm{F} 4 / 80^{+}$macrophage infiltration were significantly inhibited by TCV116, compared with the control group. ${ }^{*} P<0.01,{ }^{* *} P<$ 0.001 . Original magnification, $\times 200$. Scale bar $=100 \mu \mathrm{m}$. Quantification shown in panel C.

known to have higher expression of phosphorylation of Akt (pAkt) than LNCaP cells, ${ }^{20}$ and we have demonstrated that the expression of pAkt is markedly higher in C4-2AT6 cells than in C4-2 cells. ${ }^{21}$ Therefore, we hypothesized that the PI3K/Akt signaling pathway is a crucial factor for MCP-1 induced by Angll-AT1R signaling in CRPC.

We determined whether the Angll-AT1R axis regulates activation or phosphorylation of the PI3K/Akt signaling pathway in C4-2AT6 cells. ELISA assay showed that LY294002 significantly inhibited MCP-1 production in C42AT6 cells stimulated by Angll (Figure 5A). Next, C42AT6 cells were exposed to $10^{-8} \mathrm{~mol} / \mathrm{L}$ Angll and/or $10^{-7} \mathrm{~mol} / \mathrm{L} \mathrm{CV} 11974$ for various periods of time (2 to 30 minutes). Western blot analysis revealed that Angll induced significant pAkt within 2 minutes. This phosphor- ylation peaked at 5 minutes and persisted up to 10 minutes, and was inhibited by CV11974 at 5 minutes, although Angll and CV11974 had no definitive effect on total Akt protein during these time periods (Figure 5B). We have additionally investigated whether other Angll pathways such as MAPKs or JAK/STAT were involved in C4-2AT6 cells. Angll did not increase the phosphorylation of MAPKs (ERK1/2, JNK, and p38) and STAT3 during the time periods (see Supplemental Figure S1 at $h t t p: / /$ ajp.amjpathol.org).

\section{Discussion}

The present results have clearly demonstrated that $\mathrm{MCP}-1$ expression in $\mathrm{CaP}$ is correlated with the malignant potential of $\mathrm{CaP}$ and the PSA recurrence rate, and that MCP-1 expression in CaP was regulated by the AngllAT1R axis through the PI3K/Akt signaling pathway in vitro.

The infiltration of macrophages, or more specifically tumor-associated macrophages, presents in different types of human malignancies, and there have been numerous reports regarding the role of macrophages in malignant progression. However, there is still no clear consensus regarding the functional significance of macrophages in tumors. In CaP, only limited clinical data have been reported on macrophages that contribute to tumorigenicity and invasiveness. ${ }^{7,8,11,12}$ Moreover, it remains controversial as to whether macrophage infiltration is an indicator of the clinical outcome of CaP patients. ${ }^{7,8}$ This is one reason that it may be difficult to definitively classify subpopulations of macrophages in the tumor
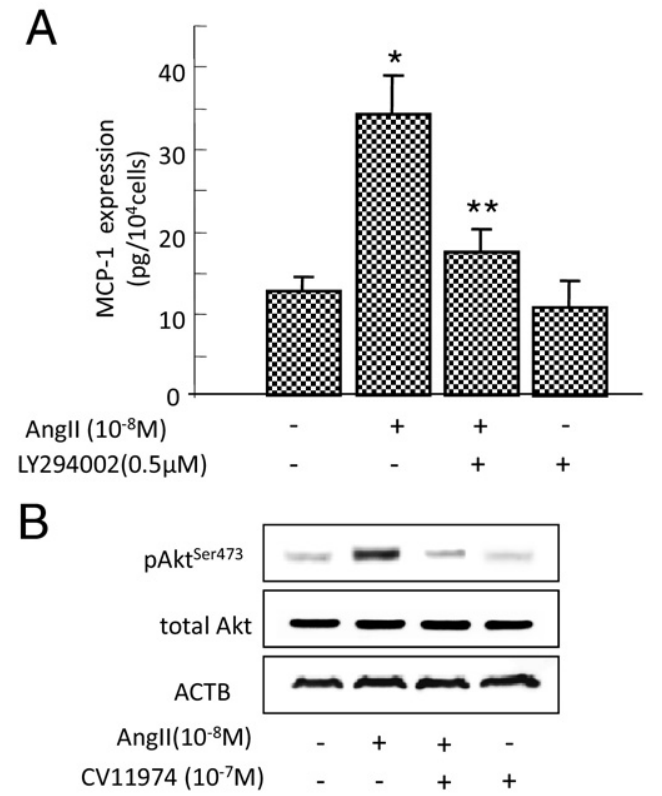

Figure 5. MCP-1 expression was regulated by AngII-AT1R PI3k/Akt signaling in CRPC cells. A: ELISA assay showed effects of AngII $\left(10^{-8} \mathrm{~mol} / \mathrm{L}\right)$ and LY294002 $(0.5 \mu \mathrm{mol} / \mathrm{L})$ in C4-2AT6 cells. MCP-1 induced by AngII was significantly inhibited by LY294002 in C4-2AT6 cells. ${ }^{*} P<0.0001$ versus control group; ${ }^{* *} P<0.001$ versus LY294002 not-treated group. B: Induction of pAkt by AngII in C4-2AT6 cells. AngII $\left(10^{-8} \mathrm{~mol} / \mathrm{L}\right)$ induced pAkt expression in C4-2AT6 cells. CV11974 $\left(10^{-7} \mathrm{~mol} / \mathrm{L}\right)$ inhibited AngII-induced pAkt expression in the cells. 
specimens. Monocytes migrate into tissues where they differentiate into resident macrophages, protect against infection, and respond to tissue injury. In cancer, some of these cells differentiate into macrophages that regulate tumor growth and angiogenesis, and thus macrophages with different functions may coexist in the tumor lesions. Counting only the number of macrophages in the tumor lesions may be insufficient to determine the clinical or pathological characteristics of the disease, and therefore, it would be necessary to investigate tumor-related chemokines as well as macrophages in the tumor lesions.

Elevated expression by both cancer and stromal cells of a number of monocyte chemoattractants has been shown to be positively correlated with increased macrophage numbers in several human tumors. ${ }^{12}$ Specifically, MCP-1 has been demonstrated to regulate monocyte/ macrophage trafficking and to be present in tumor beds, suggesting a role for this chemokine in macrophage recruitment. ${ }^{22}$ Mazzucchelli et al ${ }^{23}$ claimed that MCP-1 is expressed by fibromuscular stroma cells and basal cells of non-neoplastic glands, but not by carcinoma cells. The data appear to contradict our findings on MCP-1 expression in $\mathrm{CaP}$ cases. However, their study examined only a few CaP cases $(n=8)$ without the data on Gleason score or pathological stage, and actually showed a low-level expression of MCP-1 in the cases, which was determined by calculating numbers of the labeled cells by in situ hybridization. ${ }^{23}$ In the present study, we have demon- strated that the expression score of MCP-1 increases with Gleason score, and early-stage CaP cases show low or negligible levels of MCP-1 expression. In addition, the MCP-1 expression levels in CaP cell lines depended on the degree of their malignant phenotype. Therefore, it may be possible to explain the discrepancy by the differences in the CaP samples examined, ie, their cases may have consisted of early-stage $\mathrm{CaP}$ cases with low MCP-1 expression. Consistent with our data in the present study, Lu et al ${ }^{11}$ have reported that MCP-1 expression in the $83 \mathrm{CaP}$ specimens correlated with the Gleason score and pathological stage, and that $\mathrm{CaP}$ cells ( $\mathrm{LNCaP}$ and $\mathrm{C} 4-2 \mathrm{~B}$ cells) produced high amounts of MCP-1 compared to prostate epithelial cells in vitro.

A growing body of evidence suggests that the ability of MCP-1 to induce macrophage infiltration may provide a novel mechanism to support neoangiogenic growth of tumors, and that MCP-1 could become a target molecule for treating malignancies such as CaP. ${ }^{13,24}$ In vivo, MCP-1 small-interfering RNA in PC-3 cells (as CRPC cell line) has been shown to reduce tumor growth in a mouse model, and the treatment of mice with an anti-MCP-1 monoclonal antibody significantly suppressed the progression of prostate cancer bone metastasis in intracardiac and intratibial models. ${ }^{24}$ However, it may be difficult to completely accept anti-MCP-1 therapy for clinical use for malignancies because MCP-1 is an essential factor in

\begin{tabular}{|ll|}
\hline 0 & Tumor cells \\
0 & Immune cells \\
0 & Classical macrophage \\
0 & $\begin{array}{l}\text { Tumor-associated } \\
\text { macrophage } \\
\text { UT }\end{array}$ \\
AT1R \\
MCP-1 \\
Receptor
\end{tabular}

A

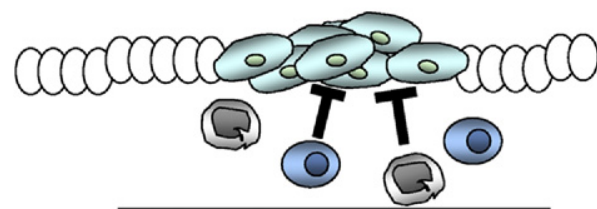

Inflammation, tumor killing

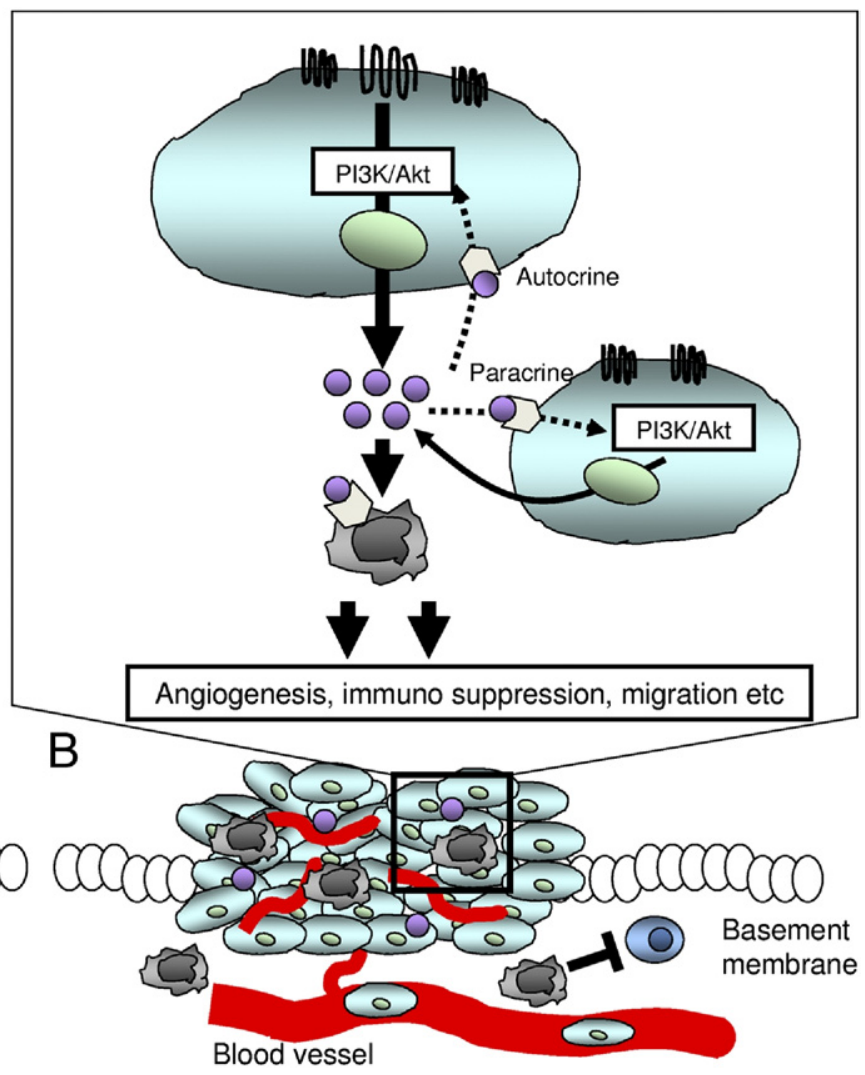

Figure 6. Scheme showing that the AngII-AT1R axis regulates MCP-1 in prostate cancer cells. In early-stage CaP, various immune cells such as cytotoxic T cells and classical macrophages infiltrate the surrounding tumor cells in response to the tumor cells (A). Advanced-stage CaP acquires high AT1R expression, which induces MCP-1 expression through the PI3K/Akt signaling pathway. MCP-1 may act in an autocrine and paracrine manner via the PI3K/Akt pathway, and induces macrophage (as tumor-associated macrophages) infiltration for angiogenesis and proliferation of CaP (B). 
biophylaxis mechanisms such as enhancement of humoral immunity and wound healing. Understanding the upstream molecular mechanism of MCP-1 expression in tumor lesions would be important for the regulation of tumor-related MCP-1 expression. Previous studies have identified both nuclear factor-kappa B (NF $\kappa$ B) and activator protein-1 (AP-1) as essential regulators of MCP-1 transcription and its induction on tumor-necrotic factor $\alpha$ stimulation. ${ }^{25}$ The Angll-AT1R axis is also known to be one of the regulators of MCP-1 expression via $\mathrm{NF} \kappa \mathrm{B}$ and AP-1 in vascular smooth muscle cells. ${ }^{26}$ In addition, recent studies have provided the evidence that the activation and/or expression of $\mathrm{NF}_{\kappa} \mathrm{B}$ is regulated by Angll in carcinoma tissues or carcinoma cells of the stomach, ${ }^{27}$ pancreas, ${ }^{28}$ and prostate. ${ }^{29}$ Because our study showed that $\mathrm{NF} \kappa \mathrm{B}$ was translocated into the nucleus after Angll stimulation and inhibited by ARB treatment in C4-2AT6 cells (see Supplemental Figure S2 at http://ajp. amjpathol. org), it seems likely that $\mathrm{NF} \kappa \mathrm{B}$ activation by Angll stimulation may be one of the main transcriptional pathways for Angll-induced MCP-1 expression in CaP cells.

Angll, which is a vasoactive peptide with a variety of effects, induces inflammation through the production of reactive oxygen species, adhesion molecules, and inflammatory cytokines such as MCP- $1 .{ }^{16}$ We have investigated whether the regulation of tumor angiogenesis through AT1R is related to the development and progression of mainly urological cancers such as renal cancer, bladder cancer, and CRPC. ${ }^{30-32}$ In particular, we previously reported that CRPC clearly showed higher AT1R expression and more aggressive angiogenesis than androgen-dependent prostate cancer. ${ }^{32}$ The present results suggest that $A R B$, which is widely and safely used to treat hypertensive disease, may contribute to the suppression of tumor growth through its inhibition of MCP-1 in CRPC.

Angll can activate multiple signaling pathways related to proliferation, such as protein kinase C, MAPK, and JAK-STAT3. Furthermore, stimulation of AT1R has been shown to trigger the PI3K/Akt, which plays a major role in a wide range of cellular processes. ${ }^{33}$ Interestingly, it has been reported that MCP-1 acts in a paracrine and autocrine manner to stimulate CaP cell proliferation and migration via the PI3K/Akt pathway. ${ }^{11}$ Our results would seem to support the possibility that one of the upstream regulators of MCP-1 by Angll is the PI3K/Akt pathway in CRPC cells. This signaling pathway in CRPC could be a novel therapeutic target, as shown in Figure 6. Although biological modulation by AT1R in tumors has not yet been elucidated, our findings indicate that the clinical application of ARB for CRPC with high AT1R expression may be promising.

In summary, our study has clearly demonstrated that MCP-1 expression in CaP is correlated with malignant potential and PSA recurrence, and that ARB had at least a partial inhibitory effect on tumor growth through the suppression of MCP-1 expression in CRPC that had acquired aggressive angiogenic properties accompanied by up-regulation of AT1R.

\section{References}

1. Jemal A, Siegel R, Ward E, Hao Y, Xu J, Thun MJ: Cancer statistics, 2009. CA Cancer J Clin 2009, 59:225-249

2. Catalona WJ: Management of cancer of the prostate. N Engl J Med 1994, 331:996-1004

3. Taichman RS, Loberg RD, Mehra R, Pienta KJ: The evolving biology and treatment of prostate cancer. J Clin Invest 2007, 117:2351-2361

4. Ryder M, Ghossein RA, Ricarte-Filho JC, Knauf JA, Fagin JA: Increased density of tumor-associated macrophages is associated with decreased survival in advanced thyroid cancer. Endocr Relat Cancer 2008, 15:1069-1074

5. Zhu XD, Zhang JB, Zhuang PY, Zhu HG, Zhang W, Xiong YQ, Wu WZ, Wang $L$, Tang $Z Y$, Sun HC: High expression of macrophage colonystimulating factor in peritumoral liver tissue is associated with poor survival after curative resection of hepatocellular carcinoma. J Clin Oncol 2008, 26:2707-16

6. Kim DW, Min HS, Lee KH, Kim YJ, Oh DY, Jeon YK, Lee SH, Im SA, Chung DH, Kim YT, Kim TY, Bang YJ, Sung SW, Kim JH, Heo DS: High tumour islet macrophage infiltration correlates with improved patient survival but not with EGFR mutations, gene copy number or protein expression in resected non-small cell lung cancer. $\mathrm{Br} \mathrm{J}$ Cancer 2008, 98:1118-1124

7. Nonomura N, Takayama H, Nakayama M, Nakai Y, Kawashima A, Mukai M, Nagahara A, Aozasa K, Tsujimura A: Infiltration of tumourassociated macrophages in prostate biopsy specimens is predictive of disease progression after hormonal therapy for prostate cancer. BJU Int 2011, 107:1918-1922

8. Shimura S, Yang G, Ebara S, Wheeler TM, Frolov A, Thomson TC: Reduced infiltration of tumor-associated macrophage in human prostate cancer: association with cancer progression. Cancer Res 2000, 60:5857-5861

9. Loberg RD, Ying C, Craig M, Yan L, Snyder LA, Pienta KJ: CCL2 as an important mediator of prostate cancer growth in vivo through the regulation of macrophage infiltration. Neoplasia 2007, 9:556-562

10. Craig MJ, Loberg RD: CCL2 (Monocyte Chemoattractant Protein-1) in cancer bone metastasis. Cancer Metastasis Rev 2006, 25:611-619

11. Lu Y, Cai Z, Galson DL, Xiao G, Liu Y, George DE, Melhem MF, Yao $\mathrm{Z}$, Zhang J: Monocyte chemotactic protein-1 (MCP-1) acts as a paracrine and autocrine factor for prostate cancer growth and invasion. Prostate 2006, 66:1311-1318

12. Zhang J, Patel L, Pienta KJ: CC chemokine ligand 2 (CCL2) promotes prostate cancer tumorigenesis and metastasis. Cytokine Growth Factor Rev 2010, 21:41-48

13. Zhang J, Lu Y, Pienta KJ: Multiple roles of chemokine (C-C motif) ligand 2 in promoting prostate cancer growth. J Natl Cancer Inst 2010, 102:522-528

14. Mantovani A, Allavena P, Sica A, Balkwill F: Cancer-related inflammation. Nature 2008, 454:436-444

15. Ager El, Neo J, Christophi C: The renin-angiotensin system and malignancy. Carcinogenesis 2008, 29:1675-1684

16. Dai Q, Xu M, Yao M, Sun B: Angiotensin AT1 receptor antagonists exert anti-inflammatory effects in spontaneously hypertensive rats. Br J Pharmacol 2007, 152:1042-1048

17. Kosaka T, Miyajima A, Shirotake S, Kikuchi E, Hasegawa M, Mikami S, Oya M: Ets- 1 and hypoxia inducible factor- $1 \alpha$ inhibition by angiotensin II type-1 receptor blockade in hormone-refractory prostate cancer. Prostate 2010, 70:162-169

18. Shariat SF, Youssef RF, Gupta A, Chade DC, Karakiewicz PI, Isbarn H, Jeldres C, Sagalowsky Al, Ashfaq R, Lotan Y: Association of angiogenesis related markers with bladder cancer outcomes and other molecular markers. J Urol 2010, 183:1744-1750

19. Zhao Y, Chen X, Cai L, Yang Y, Sui G, Fu S: Angiotensin II/Angiotensin II type 1 receptor (AT1R) signaling promotes MCF-7 breast cancer cells survival via PI3-Kinase/Akt pathway. J Cell Physiol 2010, 225: 168-173

20. Ghosh PM, Malik SN, Bedolla RG, Wang Y, Mikhailova M, Prihoda TJ, Troyer DA, Kreisberg JI: Signal transduction pathways in androgendependent and -independent prostate cancer cell proliferation. Endocr Relat Cancer 2005, 12:119-134

21. Kosaka T, Miyajima A, Shirotake S, Kikuchi E, Oya M: Phosphorylated Akt up-regulates angiotensin II type-1 receptor expression in castration resistant prostate cancer. Prostate 2011, doi: 10.1002/pros.21367 
22. Mantovani A, Bottazzi B, Colotta F, Sozzani S, Ruco L: The origin and function of tumor-associated macrophages. Immunol Today 1992, 13:265-270

23. Mazzucchelli L, Loetscher P, Kappeler A, Uguccioni M, Baggiolini M, Laissue JA, Mueller C: Monocyte chemoattractant protein-1 gene expression in prostatic hyperplasia and prostate adenocarcinoma. Am J Pathol 1996, 149:501-509

24. Loberg RD, Ying C, Craig M, Day LL, Sargent E, Neeley C, Wojno K, Snyder LA, Yan L, Pienta KJ: Targeting CCL2 with systemic delivery of neutralizing antibodies induces prostate cancer tumor regression in vivo. Cancer Res 2007, 67:9417-9424

25. Finzer $P$, Soto $U$, Delius $H$, Patzelt A, Coy JF, Poustka A, zur Hausen $H$, Rosl F: Differential transcriptional regulation of the monocytechemoattractant protein-1 (MCP-1) gene in tumorigenic and nontumorigenic HPV 18 positive cells: the role of the chromatin structure and AP-1 composition. Oncogene 2000, 19:3235-3244

26. Suzuki Y, Ruiz-Ortega M, Lorenzo O, Ruperez M, Esteban V, Egido J: Inflammation and angiotensin II. Int J Biochem Cell Biol 2003, 35 881-900

27. Kinoshita J, Fushida S, Harada S, Yagi Y, Fujita H, Kinami S, Ninomiya I, Fujimura T, Kayahara M, Yashiro M, Hirakawa K, Ohta T: Local angiotensin II-generation in human gastric cancer: correlation with tumor progression through the activation of ERK1/2, NF kappa B and survivin. Int J Oncol 2009, 34:1573-1582
28. Chehl N, Gong Q, Chipitsyna G, Aziz T, Yeo CJ, Arafat HA: Angiotensin II regulates the expression of monocyte chemoattractant protein-1 in pancreatic cancer cells. J Gastrointest Surg 2009, 13:21892200

29. Hoshino K, Ishiguro H, Teranishi J, Yoshida S, Umemura S, Kubota Y, Uemura $\mathrm{H}$ : Regulation of androgen receptor expression through angiotensin II type 1 receptor in prostate cancer cells. Prostate 2011 , 71:964-975

30. Miyajima A, Kosaka T, Asano T, Seta K, Kawai T, Hayakawa M: Angiotensin II type 1 antagonist prevents pulmonary metastasis of murine renal cancer by inhibiting tumor angiogenesis. Cancer Res 2002, 62:4176-4179

31. Kosugi M, Miyajima A, Kikuchi E, Horiguchi Y, Murai M: Angiotensin II type 1 receptor antagonist candesartan as an angiogenic inhibito in a xenograft model of bladder cancer. Clin Cancer Res 2006 , 12:2888-2893

32. Kosaka T, Miyajima A, Takayama E, Kikuchi E, Nakashima J, Ohigashi T, Asano T, Sakamoto M, Okita H, Murai M, Hayakawa M: Angiotensin II type 1 receptor antagonist as an angiogenic inhibitor in prostate cancer. Prostate 2007, 67:41-9

33. Takahashi $T$, Taniguchi $T$, Konishi $H$, Kikkawa $U$, Ishikawa $Y$, Yokoyama M: Activation of Akt/protein kinase B after stimulation with angiotensin II in vascular smooth muscle cells. Am J Physiol 1999 276:H1927-H1934 